\title{
LA CONFIGURACIÓN DEL ESPACIO PERIURBANO COMO ESCENARIO DE COMPETENCIA CRECIENTE ENTRE DIVERSOS USOS Y ACTIVIDADES: EL CASO DE ARROYO DE LA ENCOMIENDA EN VALLADOLID
}

\author{
Ricardo Ignacio CORDERO GARCÍA \\ Departamento de Geografía. Universidad de Valladolid ${ }^{1}$
}

\begin{abstract}
RESUMEN: El proceso de crecimiento urbano periférico que se observa en las ciudades medias españolas desde mediados de la década de los ochenta ha estado caracterizado por un protagonismo indiscutible de la función residencial. Las recientes inversiones orientadas a la mejora de las infraestructuras de transporte y, especialmente, el aumento del precio del suelo en las capitales han convertido al periurbano en un ámbito sumamente atractivo, no sólo para nuevas promociones de viviendas, sino también para un amplio elenco de usos y actividades. Esta es la razón que explica la creciente importancia en este espacio de polígonos industriales, grandes superficies comerciales o equipamientos deportivos, cuya presencia, como se aprecia en el caso del municipio vallisoletano de Arroyo de la Encomienda, da lugar a numerosos conflictos que es necesario solventar de manera urgente. Es aquí donde el planeamiento urbanístico está llamado a desempeñar un papel esencial, siempre y cuando se lo permitan.
\end{abstract}

PALABRAS CLAVE: Arroyo de la Encomienda, Valladolid, accesibilidad, periurbano, planeamiento.

ABSTRACT: The process of peripheral urban growth that is observed in the Spanish average cities from mid the Eighties has been characterized by an unquestionable protagonism of the residential function. The recent investments oriented to the improvement of transport infrastructures and, especially, the increase of the price of the ground in the capitals have turned to the peri-urban space an extremely attractive scope, not only for new promotions of houses, but also for a great list of uses and activities. This is the reason that explains the increasing importance in this space of industrial poligons, great commercial surfaces or sport equipments, whose presence, as it is appraised in the case of the vallisoletano municipality of Arroyo de la Encomienda, gives rise to numerous conflicts that is necessary to resolve of urgent way. It is here where the townplanning is called to play a role essential, as long as they allow it.

KEY WORDS: Arroyo de la Encomienda, Valladolid, accessibility, peri-urban space, townplanning.

$\boldsymbol{R} \boldsymbol{E} \boldsymbol{S} \boldsymbol{U} \boldsymbol{M E}:$ Le processus de croissance urbaine périphérique qui est observé dans les villes des moyennes espagnoles depuis le milieu de la décennie de des quatre-vingt a été caractérisé par un protagonisme indiscutable de la fonction résidentielle. Les investissements récents orientés à l'amélioration des infrastructures de transport et l'augmentation du prix du sol dans les capitaux ont transformé à ce qui est périurbain un cadre suprêmement attrayant, non seulement pour de nouvelles promotions de logements, mais aussi pour un vaste catalogue utilisations et activités. Celle-ci est la raison qui explique l'importance croissante dans cet espace de polygones industriels, de grandes surfaces commerciales ou équipements sportifs, dont la présence, comme il est apprécié dans le cas de la municipalité vallisoletano d'Arroyo de la Encomienda, donne lieu à de

\footnotetext{
${ }^{1}$ La realización de este artículo ha sido posible gracias a la concesión de una beca del Programa Nacional de Formación de Profesorado Universitario.
} 
nombreux conflits qu'il est nécessaire de résoudre de manière urgente. Il est ici où le plan d'aménagement urbain est appelé à jouer un rôle essentiel, pourvu qu'ils le lui permettent..

MOTS-CLÉS: Arroyo de la Encomienda, Valladolid, accessibilité, périurbain, plan d'aménagement.

RESUMO: O processo de crescimento urbano periférico que se observa nas cidades de porte médio espanholas desde meados da década de oitenta do século vinte tem sido caraterizado por um protagonismo indiscutível da função residencial. Os recentes investimentos orientados à melhoria das infraestruturas de transporte e, especialmente, o aumento do preço do solo nas capitais têm convertido o periurbano em um ambiente sumamente atrativo, não só para as novas promoções habitacionais, senão também para um amplo elenco de usos e atividades. Esta é a razão que explica a crescente importância, neste espaço, de polígonos industriais, grandes superfícies comerciais ou equipamentos esportivos, cuja presença, como se analisa no caso do município valisoletano de Arroyo de la Encomienda, dá lugar a numerosos conflitos para os quais é necessária uma solução urgente. É aquí onde o planejamento urbano está sendo chamado a desempenhar um papel essencial, sempre e quando o permitem.

PALAVRAS CHAVE: Arroyo de la Encomienda, Valladolid, acessibilidade, periurbano, planejamento.

\section{INTRODUCCIÓN}

El desarrollo y difusión de las nuevas tecnologías de la información y comunicación en el marco de la III Revolución Tecnológica ha permitido que desde mediados de la década de los ochenta haya comenzado a ser evidente en las grandes y medianas ciudades norteamericanas y europeas un cambio fundamental en el modelo de ordenación territorial, así como también en la propia concepción del espacio urbano y de aquél susceptible de poder llegar a convertirse en urbano a corto y medio plazo. Este cambio habría consistido, esencialmente, en la ruptura de la tendencia secular a la concentración de población y actividad económica, que hasta entonces había sido característica de los países desarrollados, iniciándose así una clara transformación que se caracteriza por la dispersión del hecho y las funciones otrora propiamente urbanas en el medio rural.

La asimilación de este nuevo modelo de organización territorial supone una alteración radical de la morfología y características propias de las periferias urbanas, y permite que la ciudad prolongue su extensión a lo largo de varios kilómetros, sobrepasando sus propios límites municipales y afectando también a los municipios de su entorno más inmediato, los cuales pasan a conformar el denominado "espacio periurbano". Estos núcleos constituyen el mejor exponente de la intensidad de las transformaciones morfológicas y sociodemográficas que ha conllevado este proceso ${ }^{2}$.

\footnotetext{
${ }^{2}$ En la actualidad persiste toda una amplia panoplia de términos empleados para hacer referencia al espacio circundante sobre el que las ciudades extienden su influencia. No es el propósito de
} 
Los factores responsables de estos cambios son, en verdad, muy numerosos y también complejos, hasta el punto de que el mayor protagonismo de uno u otro sobre el conjunto, o bien la ausencia de alguno de ellos, puede dar lugar a manifestaciones territoriales diferenciadas. Sin embargo, también es igualmente cierto que desde que en España tuviesen lugar las primeras experiencias en relación a este fenómeno de crecimiento urbano periférico en Madrid y Barcelona, en el resto de las ciudades españolas se observan características similares, ya que se ven afectadas por los mismos condicionantes socioeconómicos.

El caso de Valladolid no es, ni mucho menos, una excepción en este sentido, de manera que a lo largo de la década de los ochenta comenzaron a aparecer los primeros conatos de este modelo de crecimiento urbano disperso, que se fue consolidando progresivamente en años sucesivos. Así, a las diversas instalaciones industriales existentes en el entorno de las principales carreteras radiales de acceso a la ciudad, se unieron, tímidamente al principio, numerosas urbanizaciones de viviendas unifamiliares en áreas de singular valor ambiental y, frecuentemente, aisladas de otros núcleos de población, aspecto que pone en evidencia el carácter selectivo y exclusivo que reviste este fenómeno en sus comienzos. Sin embargo, a lo largo de la década de los noventa este tipo de promociones se generalizaron rápidamente y se convirtieron en accesibles no sólo para las familias de renta más elevada, sino también para buena parte de la población residente en el núcleo central de la aglomeración. Una circunstancia que, en buena medida, es la responsable de que hoy en día los municipios periurbanos sean los que registran las mayores tasas de crecimiento residencial y demográfico en términos porcentuales.

este artículo ahondar en esta cuestión, pero sirva como ejemplo que ya en el año 1985 Esmeralda González Urruela identificaba en la periferia vallisoletana la existencia de un área suburbana y otra periurbana. Según esta autora, la primera se diferenciaría de la segunda por su mayor dinamismo, su mayor presión en el uso del suelo y por ser el ámbito de continuidad con la ciudad tradicional (GonZÁlez UrRuELA, 1985, 17-36). Años más tarde, en 1998, López Trigal refrendaba esta concepción cuando, refiriéndose al caso de Castilla y León, señalaba que el crecimiento de las ciudades en el momento presente pasa necesariamente por un proceso de suburbanización y periurbanización, de su superficie, de su población y de la instalación de actividades en la ciudad (LóPEZ TRIgAL, 1998, 44-49). De hecho, otros autores, como Rafael de Miguel, llegan a hablar incluso de un espacio rururbano, que sería aquél que estando afectado por la influencia de la urbe central conserva aún su paisaje rural sin grandes impactos ni modificaciones (DE MigUEL GONZÁLEZ, 1994, 53-69). Sin embargo, en la práctica resulta prácticamente imposible delimitar el alcance de cada una de estas franjas. De ahí que exista un cierto consenso a la hora de reconocer la existencia de un área periurbana en el borde de las ciudades, entendiendo por tal el ámbito espacial contiguo a la ciudad en el que se dan mayoritariamente funciones y comportamientos propiamente urbanos, pero no parece existir tal acuerdo a la hora de hablar de un área suburbana o rururbana. 
Arroyo de la Encomienda, situado al suroeste de la capital y atravesado por la antigua Carretera Nacional 620 (Actualmente A-62), es uno de los núcleos que encaja perfectamente en este contexto que acabamos de describir, ya que entre finales de los ochenta y comienzos de los noventa iniciaba su desarrollo urbanístico con la aprobación de los Planes Parciales de Monasterio del Prado y La Vega, ambos junto a la ribera del Pisuerga, en los que el peso de los unifamiliares sobre el total de viviendas es claramente mayoritario. Gracias a las promociones de adosados, más asequibles en cuanto a precio y construidos generalmente con materiales de buena calidad, el chalé tipo, constituido por sótano y dos plantas más un bajo cubierta destinado a desván o trastero, se estandarizaba y comenzaba a ser muy demandado por los vallisoletanos, lo que permitió el inicio de nuevas urbanizaciones de similares características, así como también el tránsito hacia un modelo más intensivo de ocupación del espacio, que es claramente apreciable a partir de 1997 con motivo del inicio del ciclo expansivo del mercado inmobiliario que se ha mantenido hasta la actualidad.

Pero, a pesar de que las áreas residenciales son claramente las protagonistas en el proceso de producción de ciudad dominante en la actualidad, lo cierto es que a lo largo de la década de los noventa en el periurbano vallisoletano comenzaron a adquirir una mayor importancia de la que hasta entonces habían tenido diversas actividades industriales y también pequeñas y medianas actividades terciarias, a las que se añadieron otros usos cuya localización fuera del ámbito de la ciudad central revestía por entonces un cierto carácter novedoso. Este es el caso de los hipermercados y grandes superficies comerciales, a los que hay que sumar toda una amplia panoplia de equipamientos e instalaciones vinculadas al ocio y tiempo libre, que, junto con aquellos ámbitos que se quieren preservar de la urbanización por su atractivo natural, han contribuido a hacer del cinturón que rodea a las áreas urbanas tradicionales un espacio cada vez más extenso y complejo desde un punto de vista funcional.

Las mejoras acometidas en las principales infraestructuras radiales de acceso a la capital y el nuevo viario perimetral que enlaza todas ellas, especialmente las rondas de circunvalación interior y exterior, han permitido dotar de un alto grado de accesibilidad a un territorio cada vez más amplio en torno a la urbe central. Valladolid constituye, por tanto, una buena muestra de cómo los recursos invertidos con esta finalidad han originado en el periurbano de las ciudades actuales una creciente competencia de usos y actividades cada vez más diversas por hacerse con la propiedad del suelo, sobre todo por aquél más próximo a los principales ejes de circulación rodada que conectan cada uno de los municipios limítrofes con el núcleo vertebrador del conjunto de la aglomeración, ya que la máxima de "el mejor suelo posible, al mejor precio y con la mayor accesibili- 
dad" se ha convertido en la consigna fundamental de empresarios pertenecientes a distintos sectores y de promotores inmobiliarios.

De hecho, podríamos afirmar que la aplicación de este principio se está traduciendo progresivamente no sólo en una mayor complejidad funcional, sino también en una marcada especialización, de forma que cada uso reclama para sí su propio espacio y en la mayor parte de las ocasiones lo hace de manera exclusiva, bien sea por propia iniciativa o por las presiones de aquellas actividades más próximas. Así, a diferencia de lo que ocurría tradicionalmente en los ámbitos urbanos, donde la mezcla y heterogeneidad de funciones constituía la tónica dominante, incluso en los barrios de mayor prestigio social, la actual expansión periurbana introduce una marcada segregación funcional. Para evitarlo, se ha de apostar firmemente por un modelo de planificación territorial concebido a escala del conjunto de la aglomeración que permita superar las tensiones existentes a nivel intermunicipal y que garantice un aprovechamiento racional y eficiente de los recursos e infraestructuras existentes.

\section{EL PROTAGONISMO INDISCUTIBLE DE LAS FUNCIONES RESIDENCIAL E INDUSTRIAL EN LA OCUPACIÓN DEL SUELO PERIURBANO}

Si observamos la distribución de usos del suelo establecida por el Plan General de Ordenación Urbana de Arroyo de la Encomienda, puede constatarse como, efectivamente, el uso residencial es el protagonista indiscutible en el mismo, ya que el $70 \%$ de la superficie clasificada como urbanizable se adscribe a esta categoría. Una situación claramente diferente a la acontecida durante los años sesenta y setenta en los que la única expansión del tejido urbanizado se realizó a raíz de las industrias que se instalaron en los márgenes de la Carretera $\mathrm{N}-620$, muchas de las cuales optaron por ese emplazamiento a partir de la declaración de Valladolid como Polo de Desarrollo en 1964, siendo algunos de los ejemplos más significativos Dulces y Conservas Helios, S. A. y la antigua Cartonera Española, cuyas instalaciones fueron reconvertidas y pertenecen en la actualidad a la compañía irlandesa Smurfit Ibersac, S. A. Y es que, además de los incentivos económicos ligados al Polo de Desarrollo, estas empresas consiguieron aunar, por un lado, las ventajas de una localización periférica, que se tradujeron esencialmente en una mayor accesibilidad y un menor precio del suelo sobre el que se asentaron, y, por otro, aquéllas derivadas de la proximidad a una ciudad de la entidad de Valladolid, que ya entonces constituía un importante mercado de consumo y, además, permitía tener asegurada la disponibilidad de mano de obra.

Es cierto, no obstante, que hoy en día la actividad industrial tiene una importancia secundaria para los ayuntamientos de los núcleos periurbanos, puesto que 
son mucho más sustanciosas las aportaciones realizadas a las arcas municipales por las nuevas promociones de viviendas en concepto de licencias de obras, pero, al mismo tiempo, el ejemplo de Arroyo nos muestra como también se tiende a buscar una complementariedad entre residencia y actividad económica, ya sea de carácter industrial o terciario. Con ello se pretende buscar alternativas que permitan no hipotecar el desarrollo de un municipio en torno a la función residencial, lo cual, cómo veremos, puede originar tensiones por el aprovechamiento del suelo o por la persistencia de un determinado uso en un emplazamiento concreto.

\section{Del éxito inicial de los unifamiliares al predominio actual de la vi- vienda colectiva: nuevas demandas en un contexto de crecimiento inmobiliario}

Ciertamente, un primer factor a destacar responsable de las transformaciones en el ámbito periurbano consiste en la búsqueda de nuevos lugares para vivir por parte de los propios habitantes de las aglomeraciones urbanas que, al igual que ya ocurriese con los modelos de ciudad jardín propios de finales del siglo XIX, demandan nuevas áreas residenciales a las que puedan huir de la congestión, de la contaminación y de los problemas asociados a un estilo de vida urbano tradicional (CALDERÓN, 2002, 43-63). Y en esta huída de la ciudad, los ámbitos mejor valorados son los que poseen un especial atractivo desde el punto de vista de sus recursos naturales. Si a eso añadimos proximidad a la ciudad en la que se desarrolla su actividad laboral, obtendremos los espacios socialmente más apetecidos.

Así, la urbanización tiende a ocupar de forma preferente las áreas de mayor calidad ambiental en el entorno de las ciudades, en particular las vegas y riberas de los ríos, dado su tradicional papel de corredores en los que se han ido implantando a lo largo del tiempo las principales vías de comunicación que enlazan las áreas urbanas (MONCLÚs, 1998, 143-167). Uno de estos espacios de gran atractivo paisajístico vendría delimitado por los ríos Duero y Pisuerga al suroeste de la capital vallisoletana, siendo ésta, precisamente, una de las razones fundamentales que explican el hecho de que las urbanizaciones residenciales emplazadas en este ámbito hayan adquirido un notable prestigio social y desde sus orígenes hayan estado reservadas a población con un cierto nivel de renta (GARCÍA FERNÁNDEZ, 2000, 279).

Lógicamente, esta ocupación resulta posible gracias a que las rentas diferenciales de la agricultura, actividad dominante en la mayoría de estas áreas, son claramente inferiores a las urbanísticas, lo que genera una acusada tensión hacia la transformación económica del suelo rústico, que rápidamente pasa a ser un objetivo del mercado inmobiliario espoleado por ese ansiado reencuentro con la 
naturaleza que demandan los habitantes de la ciudad (GARCÍA-BELLIDO, 2002, 277-322). Si a ello añadimos la existencia de una normativa poco o nada restrictiva con las nuevas urbanizaciones de unifamiliares, especialmente en los núcleos del entorno de las grandes urbes, que buscan con ello iniciar su desarrollo y despegue económico, puede entenderse fácilmente que acabe consolidándose la urbanización en estos ámbitos.

Dos magníficos ejemplos de nuevas áreas residenciales cuyo origen cabe enmarcar en este contexto serían los Planes Parciales de Monasterio del Prado y de La Vega con 185 y 1.030 viviendas respectivamente, cuya ocupación se inició a comienzos de los noventa y acabó prolongándose durante toda la década e incluso parte de la actual. Estas actuaciones se concibieron originariamente de forma absolutamente aislada, precisamente con el fin de mantener el carácter "exclusivo" de las mismas, y junto con aquéllas llevadas a cabo en los dos núcleos de población originarios del municipio: Arroyo núcleo histórico y "La Flecha", fueron las responsables de que entre 1988 y 1998 el 70,32\% de las viviendas construidas en Arroyo de la Encomienda fuesen de tipo unifamiliar, con una dimensión media en torno a los 112,92 $\mathrm{m}^{2}$ útiles/vivienda, destacando especialmente las promociones de adosados en torno a las 15 o 20 viviendas, como las acometidas por Proyectos y Construcciones BMAG, S. L., Hergumar La Vega, S. A., DECOVAMA, S. A. o Lomarte Promociones S. L., entre otras.

Como norma general, en todas estas promociones, si bien a efectos publicitarios se siguen resaltando las referencias a los atractivos característicos del ámbito en el que se encuentra el producto ofertado, lo cierto es que en la mayor parte de las ocasiones ese supuesto reclamo ambiental de la urbanización queda reducido a su mínima expresión, cuando no se prescinde directamente del mismo, y es, en realidad, la propia vivienda unifamiliar la que se convierte en garante de esa mejor calidad de vida tan ansiada por los futuros compradores. Si, además, tenemos en cuenta que por el precio de un piso de entre 90 y $100 \mathrm{~m}^{2}$ útiles en la capital puede adquirirse un chalé en muchos de los núcleos limítrofes con la misma, fácilmente puede entenderse la rápida proliferación de esta tipología edificatoria y su papel en la expansión periurbana, poniendo, a su vez, de relieve cómo el factor que incide en mayor medida en el precio final del producto inmobiliario, el coste del suelo, es superior en Valladolid con respecto a los municipios de su entorno, lo que genera, en definitiva, una pérdida de competitividad de la ciudad central (AYUNTAMIENTO DE VALLADOLID, 2004, 31).

Este diferencial se manifiesta aún con mayor claridad a partir de 1997, año en el que se iniciaba el ciclo expansivo del mercado inmobiliario y con él una fuerte subida de los precios, hasta el punto de que entre el último trimestre de 1997 y el mismo de 2002 el incremento fue del $86 \%$, lo que significa que en los últimos 7 u 8 años habríamos superado con creces el umbral de duplicación 
(RODRÍGUEZ, 2003, 163-183). Esta circunstancia es determinante para entender la progresiva pérdida de importancia de la vivienda unifamiliar en detrimento de la colectiva, lo cual comenzó a ser evidente a partir de entonces, puesto que, ante el recién estrenado contexto de expansión económica, este tipo de inmuebles eran los que permitían obtener una mayor rentabilidad de la inversión realizada por los promotores en la adquisición de suelo. De hecho, a diferencia de lo ocurrido en años anteriores, el $64 \%$ del total de las viviendas construidas o iniciadas en Arroyo de la Encomienda entre 1999 y 2004 responderían a esta tipología constructiva, pasando a ser dominantes las promociones de tres y cuatro alturas e iniciándose un aumento considerable de la superficie movilizada por actuación.

Cuadro 1. Sintesis de la evolución de la actividad constructiva en Arroyo de la Encomienda por etapas de estudio

\begin{tabular}{lcc}
\hline & Etapa 1988-1998 & Etapa 1999-2004 \\
\hline Porcentaje de viviendas construidas sobre el total & $28,85 \%$ & $71,15 \%$ \\
Porcentaje de viviendas unifamiliares & $70,32 \%$ & $36 \%$ \\
Dimensión media de las viviendas (en m $\mathrm{m}^{2}$ útiles/viv.) & $112,92 \mathrm{~m}^{2}$ & $95,72 \mathrm{~m}^{2}$ \\
\hline
\end{tabular}

FUENTE: Archivo Municipal de Arroyo de la Encomienda. Expedientes de Obras. Elaboración propia.

De esta forma, a finales de la década de los noventa, asistíamos al verdadero despegue urbanístico de este municipio y de todos aquéllos situados en el entorno de la capital, gracias, por un lado, a esta nueva etapa expansiva del mercado inmobiliario, pero también, y en relación directa con ello, a la aprobación de una nueva generación de normativas de planeamiento urbano claramente favorables a los intereses de la promoción inmobiliaria. Unos promotores que durante los años previos a la actual coyuntura alcista habrían logrado hacerse a un precio asequible con buena parte del suelo de estos núcleos destinado otrora a la actividad agraria, exigiendo, rápidamente, su reclasificación a las corporaciones locales para poder iniciar así su transformación urbanística.

El caso de Arroyo de la Encomienda es paradigmático en este sentido, ya que en 1999 se aprobó una Revisión de las Normas Subsidiarias Municipales en las que se reclasificó buena parte del suelo considerado como no urbanizable, siendo, en realidad, un preludio de lo que supondría la aprobación del Plan General de Ordenación Urbana en 2003, cuyas determinaciones en materia urbanística pueden considerarse aún más ambiciosas que las establecidas en las anteriores Normas, en la medida en que este nuevo instrumento de ordenación general clasifica como urbano o urbanizable el 56,34\% del total de la superficie del término municipal y prevé un incremento poblacional de casi 40.000 habitantes para 
los próximos años, que se añadirían a los 6.639 existentes a 31 de diciembre de 2004.

Una magnífica prueba de este notable incremento de la actividad constructiva vendría dada por el hecho de que en los últimos seis años se enmarcarían el $71,15 \%$ de las viviendas construidas o iniciadas en el municipio desde 1988, si bien es cierto que, como consecuencia del creciente predominio de las edificaciones colectivas en las nuevas promociones, se aprecia una disminución en la superficie útil media de las mismas, que habría pasado a situarse en los 95,70 $\mathrm{m}^{2}$ útiles/vivienda. Existen, sin embargo, determinados ámbitos en los que se supera con creces este valor, tal y como sucede en el caso del conjunto residencial “Sotoverde Casas \& Golf”, promovido por la inmobiliaria gallega Fadesa, y que consta de un total de 569 unifamiliares distribuidos en adosados, pareados y agrupados, así como de otras 219 parcelas vendidas a particulares en las que actualmente se está llevando a cabo la construcción de otros tantos chalés exentos.

Esta urbanización constituye, en definitiva, un ejemplo de cómo, pese al predominio de las promociones de vivienda colectiva, los unifamiliares, cada vez más alejados de la ciudad, siguen teniendo un cierto atractivo para los vallisoletanos y, en general, para la población residente en ámbitos urbanos tradicionales. No deja de ser llamativo que este conjunto residencial, pionero en su emplazamiento al noroeste del municipio, se ubique en el ámbito donde el Plan General define los grandes sectores de suelo urbanizable que canalizarán el crecimiento urbanístico de Arroyo de la Encomienda para los próximos años con una superficie total de más de 250 Has. y una previsión de 8.200 nuevas viviendas, la mayor parte de las cuales, a tenor del planeamiento de desarrollo aprobado en la actualidad, se dispondrán en bloques de cuatro y cinco alturas.

El hecho de que la construcción de los nuevos polígonos industriales de titularidad privada y municipal con una superficie total próxima a las 150 Has. se esté acometiendo justo enfrente del gran paquete de suelo en el que se ubicarán estas nuevas áreas residenciales, al otro lado de la carretera comarcal que conduce al municipio de Ciguñuela, está suscitando numerosas quejas ante la Administración local por parte de promotores y particulares. Se trata, en suma, del último capítulo de un conflicto que cada vez comienza a estar más en boga en los ámbitos periurbanos, aquél originado por la contigüidad espacial de nuevas áreas residenciales y actividades industriales, y que no constituye el único ejemplo que podemos encontrar en este municipio del suroeste vallisoletano. 


\section{El proceso de relocalización industrial en la antigua $\mathrm{CN}-620$ como síntoma evidente del conflicto entre nuevas áreas residenciales e ins- talaciones industriales}

Como ya hemos señalado, durante los años sesenta y setenta se instalaron en Arroyo de la Encomienda algunas de las empresas de mayor relevancia en el perfil industrial del municipio en la actualidad, tanto en lo que se refiere a volumen de suelo ocupado como a número de trabajadores. Dado que por aquél entonces nada hacía presagiar el fuerte crecimiento que iba a tener el conjunto del espacio periurbano vallisoletano, estas industrias obtuvieron fácilmente la preceptiva licencia municipal para construir sus instalaciones en una o varias parcelas de suelo rústico junto a la actual A-62, de tal manera que no fue hasta la segunda mitad de los años noventa, a raíz del desarrollo urbanístico que estaba experimentando entonces la localidad, cuando los responsables políticos locales comenzaron a plantearse seriamente la necesidad de reubicar dichas actividades en un nuevo emplazamiento más alejado de las áreas residenciales.

Así, en la Revisión de las Normas Subsidiarias de 1999 se reconocía la conveniencia de realojar las industrias existentes en los bordes de lo que entonces era la Carretera N-620, puesto que por su proximidad a los núcleos de población de mayor entidad del municipio podrían generar molestias a los vecinos en cuanto a ruidos y a olores. Es más, en el citado instrumento de planeamiento general se clasificaba el suelo ocupado por estas industrias como urbano consolidado, y de forma pormenorizada se le asignaba la calificación de "Unidades de Sustitución Industrial". Sin embargo, durante el periodo de vigencia de estas Normas fue imposible materializar estas previsiones, ya que para estas áreas se establecía una densidad máxima de $25 \mathrm{Viv}$./Ha. y un índice de edificabilidad de $0,4 \mathrm{~m}^{2} / \mathrm{m}^{2}$, lo que suponía una intensidad de uso demasiado baja como para que fuese rentable para los propietarios.

Posteriormente, el nuevo Plan General de Ordenación Urbana asumió este objetivo, planteándose nuevamente la forma más adecuada de llevar a efecto esta reubicación sin que ello implicase la pérdida de las actividades económicas y de los puestos de trabajo a ellas asociados. En este sentido, el propio Plan reconoce la imposibilidad de que el Ayuntamiento pueda sufragar este proceso con fondos públicos, de manera que se estima que la única solución posible para la consecución de este objetivo pasa por permitir el aprovechamiento residencial o terciario en unas condiciones lo suficientemente ventajosas como para que las empresas instaladas en las Unidades de Sustitución pudieran financiar con ello su propia relocalización en las nuevas áreas industriales habilitadas a tal efecto dentro del propio término municipal. 
Con este propósito a comienzos de 2003 el Ayuntamiento de Arroyo de la Encomienda firmaba una serie de convenios con las empresas instaladas en estas Unidades de Sustitución comprometiéndose a clasificar estos terrenos como suelo urbano en el Plan General de Ordenación Urbana, incluyendo en el mismo la ordenación pormenorizada previamente aceptada por los propietarios del suelo. Según se recogía en estos documentos, los terrenos correspondientes a las Unidades de Sustitución sólo podían ser considerados como suelo urbano consolidado al existir edificaciones en la totalidad de los solares. En consecuencia, por aplicación de la Ley 5/1999, de Urbanismo de Castilla y León, les correspondería un aprovechamiento máximo de $100 \mathrm{Viv}$./Ha. y una edificabilidad de $1,5 \mathrm{~m}^{2} / \mathrm{m}^{2}$ para el desarrollo de los nuevos usos en la unidad ${ }^{3}$.

A su vez, las empresas firmantes asumían el compromiso de reubicar sus instalaciones fabriles dentro del propio término municipal de Arroyo en un plazo máximo de 8 años, garantizando también su permanencia en la localidad por un mínimo de 20 desde la entrada en vigor del mencionado Plan General, es decir, hasta el año 2023. Para ello se reservaban las 30,57 Has. del futuro polígono industrial a desarrollar por iniciativa de la Administración local en el noroeste del municipio (Véase FIGURA 5).

No obstante, pese a los esfuerzos realizados, estos convenios ya no están en vigor en la actualidad, puesto que la Comisión Territorial de Urbanismo dictaminó en abril de 2003 que el suelo correspondiente a estas Unidades de Sustitución no podía ser calificado como urbano consolidado, sino que debía considerarse como suelo urbano no consolidado ${ }^{4}$. Esto obligaba, lógicamente, a una reducción considerable del aprovechamiento máximo permitido, de tal manera que, en aplicación del artículo anterior de la legislación autonómica, se pasaría de 100 Viv./Ha. a 50 Viv./Ha., así como a una edificabilidad de $0,75 \mathrm{~m}^{2} / \mathrm{m}^{2}$, lo cual incumple claramente lo estipulado en los acuerdos firmados con la corporación municipal y, al mismo tiempo, hace que plantearse la reubicación resulte ruinoso para estas actividades, especialmente en el caso de las que ocupan una mayor extensión, como sucede con las factorías de Smurfit Ibersac, S. A. y Dul-

\footnotetext{
${ }^{3}$ En concreto, según los convenios urbanísticos firmados, sería de aplicación el artículo 36.1.b de la Ley de Urbanismo de Castilla y León, que establece lo siguiente: "En suelo urbano consolidado, cuando ya existan más de 100 viviendas o 15.000 metros cuadrados construidos por hectárea, el planeamiento no podrá contener determinaciones de las que resulte un aumento del aprovechamiento o de la densidad de población totales".

${ }^{4}$ A este respecto la Comisión Territorial de Urbanismo señalaba que "...dado el uso que se propone a estos sectores, con sustitución de uso industrial por residencial, que implica la demolición de la industria y dejar gran superficie de terreno libre para superficie residencial, sin infraestructuras interiores que pudieran justificar este tipo de suelo, no podrá ser suelo urbano consolidado, debiendo calificarse como suelo urbano no consolidado".
} 
ces y Conservas Helios, S. A., cuya superficie asciende a un total de $122.919 \mathrm{~m}^{2}$ y $74.268 \mathrm{~m}^{2}$, respectivamente.

En realidad, todo parece indicar que las empresas emplazadas en este ámbito están esperando a que el municipio alcance los 20.000 habitantes, lo que convertiría en rentable la operación, pues podrían beneficiarse de un aprovechamiento de $70 \mathrm{Viv}$./Ha. Esta situación ha provocado que uno de los objetivos fundamentales del planeamiento municipal haya quedado seriamente comprometido, prolongándose así de forma prácticamente indefinida el logro de una solución a este conflicto que, además, tenderá a agravarse a medida que se vaya completando el desarrollo de los nuevos sectores de suelo urbanizable.

Un proceso de naturaleza muy similar a este, aunque en esta ocasión a una escala mucho más reducida y sin la existencia de ningún tipo de acuerdo previo entre propietarios y Ayuntamiento, lo encontramos en el entorno del Camino de Zaratán, situado al este del núcleo de La Flecha, justo en el límite con el término municipal de la capital. A lo largo de los años cincuenta y sesenta comenzaron a surgir en este ámbito pequeñas naves industriales de diversa índole que fueron aumentando y consolidando su presencia durante las décadas siguientes, pero a medida que avanzaba la década de los noventa muchas de estas antiguas instalaciones fueron sustituidas por nuevas promociones residenciales que, aunque en su mayoría no han sido de mucha entidad, una a una han terminado por desplazar a este tipo de actividades.

La transformación que ha conocido el Camino de Zaratán en los últimos años ha sido de tal relevancia que a mediados de 2005 fue necesario acometer una importante actuación de remodelación y mejora de la urbanización en todo su recorrido, la cual, por otro lado, fue muy cuestionada por los representantes municipales de la capital, ya que el proyecto incluía la construcción de un aparcamiento en la margen derecha de esta importante vía de acceso al núcleo de La Flecha y, por consiguiente, en suelo vallisoletano. La consecución de un acuerdo entre el consistorio de Arroyo y la Junta de Compensación de la Unidad de Actuación única del Sector 27.1 del Plan General de Ordenación Urbana de Valladolid, conocido como "Las Raposas I" y clasificado como suelo urbanizable de uso industrial, permitió ejecutar, al fin, la operación, pero no sin dar lugar a un lamentable cruce de acusaciones entre los regidores de ambos municipios, tal y como apareció publicado en la prensa local a finales de 2005 .

\section{LA SUPERPOSICIÓN DE DIFERENTES LÓGICAS ESPA- CIALES EN UN ÁMBITO DE GRAN COMPLEJIDAD Y DE DIFÍCIL ARTICULACIÓN}

No cabe duda de que el intenso desarrollo urbanístico que caracteriza en la ac- 
tualidad a los municipios del entorno periurbano, y todo lo que ello conlleva en cuanto a la necesidad de acometer nuevas inversiones en materia de transporte, abastecimiento y equipamientos en general, se ha convertido en los últimos años en una fuente inagotable de conflicto entre estos núcleos y las urbes centrales. Así, mientras que los primeros exigen a las capitales una mayor colaboración e implicación en la búsqueda de soluciones comunes para compartir sus infraestructuras, construir otras nuevas o en cuanto a la prestación de determinados servicios aludiendo a criterios de sostenibilidad, eficiencia y racionalidad económica, éstas, en cambio, no siempre se muestran tan dispuestas, ya que, al poseer las suyas propias, se suele afirmar que los beneficios para la ciudad serían mínimos o nulos, al tiempo que ello contribuiría a hacer aún más atractiva la oferta residencial de estas localidades.

Este último aspecto constituye, en definitiva, el principal escollo a la hora de plantear fórmulas que permitan una mayor coordinación intermunicipal y que eviten el despilfarro de los escasos recursos existentes, especialmente en el caso de los pequeños ayuntamientos. Si a eso sumamos la existencia de un contexto económico en el que, una vez más, el suelo urbano o urbanizable a bajo precio se ha convertido en un bien supuestamente escaso y, como tal, en objeto de deseo por un elenco cada vez más amplio de empresarios, promotores y agentes de la propiedad, puede entenderse fácilmente la enorme dificultad de llevar a la práctica un modelo de planificación territorial a escala supramunicipal capaz de satisfacer intereses que, en ocasiones, pueden considerarse radicalmente opuestos.

\section{La reciente aparición de nuevos usos y actividades: el papel de los modernos centros comerciales y los equipamientos deportivos liga- dos a las nuevas urbanizaciones}

Partiendo de esta base, y sin olvidar el importante papel desempeñado por las funciones residencial e industrial en el proceso de creación y desarrollo de nuevas periferias urbanas, podemos afirmar que en los últimos años el espacio periurbano se ha convertido también en un ámbito especialmente atractivo para algunas de las nuevas formas de organización de la actividad terciaria, ya sean los hipermercados, que cuentan con una mayor tradición, o los grandes centros comerciales que, además de comercio especializado, incluyen restauración y una oferta diversa destinada al ocio (salas de cine, discotecas, etc.). De esta forma, lo que se persigue con esta notable variedad de servicios es, por un lado, atraer a un mayor número de clientes, pero también prolongar su estancia en ellos el máximo tiempo posible.

Con estas premisas es fácil entender que los hipermercados y nuevos centros comerciales tiendan a localizarse cada vez en mayor medida en los núcleos del 
entorno de las grandes ciudades, puesto que allí pueden encontrar todo lo que necesitan en mejores condiciones que en la capital, y que es fundamentalmente proximidad a las grandes infraestructuras de transporte y suelo disponible a bajo precio, ya que, además de la parcela destinada propiamente a la actividad terciaria, requieren una amplia superficie de aparcamiento. De esta forma, se convierten en "nuevas áreas de centralidad urbana", cuya accesibilidad es máxima, si bien es cierto que, a diferencia de lo que ocurría con los centros históricos tradicionales, lo es casi en exclusiva a través del vehículo privado (LÓPEZ, 1994, 71-77). Además, dado que aseguran una importante dotación comercial, también hay que tener en cuenta que frecuentemente suelen actuar como motores del crecimiento urbano en el área en el que se asientan, lo que acentúa su importancia y permite comprender el interés de los municipios periurbanos por contar con uno de estos grandes equipamientos terciarios.

En este sentido, la apertura de Pryca en el año 1992 convirtió a Arroyo de la Encomienda en el primer núcleo del periurbano vallisoletano en contar con un hipermercado en su término municipal, el cual, sin embargo, se localizó frente a La Flecha, al otro lado de la Carretera N-620, y prácticamente en el límite con la capital. Una circunstancia que fue posible gracias a que el Plan Parcial "Monasterio del Prado", aprobado en octubre de 1988, preveía un sector de uso residencial y otro de uso mayoritario industrial, en cuya definición se incluía el concepto de almacén, y, al mismo tiempo, permitía completar este aprovechamiento mayoritario con uso comercial. A ello hay que añadir el hecho de que en este ámbito la ordenación detallada tampoco definía una parcela máxima, circunstancia que posibilitó la ocupación de dicho espacio por un único edificio.

En 1999 la Revisión de las Normas Subsidiarias Municipales clasificó como suelo urbano consolidado de uso comercial los $52.460 \mathrm{~m}^{2}$ de superficie en los que se ubica el actual Hipercor, incluyendo tanto el hipermercado como su aparcamiento, categoría que se mantuvo posteriormente en el Plan General de Ordenación Urbana, en virtud del convenio urbanístico firmado entre la corporación local y el representante de esta sociedad en septiembre de 2002. Un acuerdo cuya trascendencia real va mucho más allá del mero mantenimiento de la clasificación del uso del suelo, ya que estableció las condiciones para una importante transformación espacial en este ámbito. En virtud de este documento, y a petición de la empresa integrada en el grupo de Isidoro Álvarez, el Ayuntamiento de Arroyo adquiría también el compromiso de definir en el Plan General una ordenanza específica de grandes equipamientos comerciales y usos compatibles con un aprovechamiento de $1 \mathrm{~m}^{2} / \mathrm{m}^{2}$, que posibilitase la ampliación y reforma de la edificación existente. Un aumento de superficie que se justificaba en dicho convenio aludiendo a la necesidad de mejorar la dotación terciaria del municipio ante el fuerte incremento de población previsto para los próximos 
años y que, a su vez, permitiría que la localidad pudiese ser considerada autónoma en esta materia.

Por otro lado, a través del presente convenio urbanístico, Hipercor, S. A. asumía también una serie de compromisos con el Ayuntamiento de esta localidad, pudiendo destacar algunos de ellos: ejecutar a su costa el enlace subterráneo entre el viario interno del centro comercial y la prolongación de la vallisoletana Avenida de Salamanca en ambos sentidos de circulación así como con el núcleo de La Flecha, o el compromiso de ceder el suelo necesario y ejecutar el vial lateral de acceso a las instalaciones existentes por el este de la parcela comercial. Asimismo, una vez obtenida la preceptiva licencia comercial específica para grandes superficies comerciales ante la Consejería de Industria, Comercio y Turismo de la Junta de Castilla y León y las correspondientes licencias municipales de construcción y actividad, Hipercor se comprometía a abonar al consistorio de Arroyo de la Encomienda la cantidad de tres millones de euros (500 millones de las antiguas pesetas) para posibilitar que por parte de la corporación local pudieran acometerse las obras necesarias que permitan la conversión de la antigua CN-620 en avenida urbana; vía fundamental de acceso a la capital ${ }^{5}$.

En virtud de estos compromisos, especialmente del último, se puede entender el interés que ha suscitado en Arroyo el hecho de que Hipercor pueda acometer la ampliación de sus instalaciones, ya que la aportación de esta sociedad resulta esencial para financiar el proyecto de remodelación de la antigua carretera nacional que atraviesa el municipio. Según el Plan General, el coste de ejecución de esta iniciativa ascendería a un total de 6.500.000 € y constituiría una de las actuaciones estrella del actual equipo de gobierno en materia de infraestructuras viarias, ya que se estima que mejoraría sustancialmente la comunicación entre los cinco núcleos de población existentes en la actualidad en este término: Arroyo (núcleo histórico), Monasterio del Prado, La Flecha, La Vega y Sotoverde (Véase FIGURA 1).

A finales de 2004 la prensa local recogía esta noticia, señalando que El Corte Inglés había presentado un proyecto para la construcción de un centro comercial de $40.000 \mathrm{~m}^{2}$ en los terrenos destinados al aparcamiento de su hipermercado en Arroyo de la Encomienda ${ }^{6}$. Dicha actuación habría sido defendida ya ante los responsables de la Junta de Castilla y León en una reunión durante el proceso

${ }^{5}$ La Ley 6/2002, de 19 de diciembre, de Comercio de Castilla y León establece en su artículo 17.c que tendrán la consideración de grandes establecimientos comerciales "los establecimientos comerciales individuales o colectivos con una superficie de venta al público igual o superior a $1.000 \mathrm{~m}^{2}$ en municipios con menos de 10.000 habitantes", que sería el caso de Arroyo de la Encomienda en la actualidad.

${ }^{6}$ El Norte de Castilla, 31-10-2004, 4-11-2004, 5-11-2004 y 10-11-2004. 
de elaboración del Plan de Equipamientos Comerciales de la comunidad, ya que de su aprobación depende que el gobierno regional pueda, finalmente, conceder la licencia necesaria para poder llevarlo a la práctica. Pese a que aún no se ha tomado ninguna decisión al respecto, el mero anuncio de las intenciones de este grupo empresarial suscitó un acalorado debate entre representantes del consistorio vallisoletano y los alcaldes de los municipios periurbanos acerca de cual sería el mejor emplazamiento para las nuevas grandes superficies. De esta forma, mientras que los primeros señalaban la necesidad de que éstas abriesen en la capital por ser donde se concentra la demanda, el resto defendían su autonomía para decidir sobre la cuestión.

En cualquier caso, independientemente de la mayor o menor validez de los argumentos de unos y otros, lo cierto es que la firma del convenio urbanístico con el Ayuntamiento de Arroyo de la Encomienda y los compromisos adquiridos por ambas partes denotan una clara voluntad de acometer dicha operación en los próximos años, una vez se hayan superado todos los condicionantes existentes y se hayan ejecutado los proyectos de la Ronda Exterior Sur de Valladolid y de conversión en avenida urbana del tramo señalado de la antigua Carretera N-620. Estas actuaciones permitirán incrementar aún más la accesibilidad del futuro centro comercial de $E l$ Corte Inglés, el cual, por otro lado, constituye un claro ejemplo del fuerte atractivo que ejerce el suelo periurbano sobre este tipo de actividades, cuya lógica espacial se rige por la necesidad de alcanzar la mayor cuota de mercado posible.

Un principio que, sin embargo, no es del todo aplicable a otro de los usos que, junto con los espacios destinados a estas nuevas funciones terciarias, reviste un carácter más novedoso en el entorno de las grandes y medianas ciudades. Se trata, concretamente, de los múltiples y variados equipamientos que han ido apareciendo en los últimos años ligados a la práctica del deporte. En numerosas ocasiones se trata de actividades que precisan de un elevado consumo de suelo, como por ejemplo los campos de golf, lo que hace difícil su acomodo en la ciudad central, que es donde se concentra la demanda de este tipo de servicios vinculados al ocio y al tiempo libre, de tal forma que se ven obligados a buscar una localización alternativa en otros municipios próximos a la capital (BARRADO, 1998, 145-162).

Sin embargo, lo cierto es que en otros muchos casos la concentración de este tipo de equipamientos en núcleos del entorno periurbano no puede explicarse únicamente en función de la dificultad de conseguir el suelo necesario para ello en la ciudad central, sino que más bien se trata de una estrategia adoptada a conciencia por estos municipios. Con ello pretenden, por un lado, ofrecer un servicio a su población del que antes se carecía, o bien era muy escaso, y, por otro, lograr disponer de un importante activo que permita la dinamización y re- 
valorización del atractivo social de la localidad, con el fin de poder atraer un mayor volumen de efectivos demográficos y afianzar así su expansión urbanística. De hecho, frecuentemente aparecen vinculados a las nuevas promociones exaltándose como símbolo de calidad y exclusividad en los folletos publicitarios de las mismas, pudiendo destacar como ejemplo el lema con el que se difundió comercialmente el conjunto residencial Sotoverde al que hicimos referencia anteriormente: "Casas \& Golf".

En realidad, se parte de la dificultad que en muchos casos encuentran los habitantes de la ciudad central para acceder a este tipo de equipamientos, bien sea por la lejanía de los mismos a su domicilio o por el alto coste de utilización, incluso en aquéllos de carácter público. Una circunstancia que es cada vez más evidente en las instalaciones deportivas más minoritarias, como es el caso de los campos de golf, pistas de patinaje, piscinas públicas, etc. Ante esta situación, la estrategia adoptada por algunos núcleos periurbanos consiste precisamente en disponer de una oferta de actividades de este tipo lo más amplia y diversificada posible, siendo éste un aspecto prioritario en la planificación urbana con el fin de garantizar su proximidad a la totalidad de los ciudadanos.

Este sería el caso de Arroyo de la Encomienda, que en los últimos años ha acometido inversiones en equipamientos deportivos por valor de 7,4 millones de euros, superando así el déficit tradicional que tenía el municipio en este tipo de instalaciones, lo cual ha sido posible en buena medida gracias a las aportaciones en concepto de cesiones urbanísticas obligatorias y a los ingresos procedentes de las licencias de obra nueva. En concreto, los proyectos más llamativos se localizan en el sector noroeste, donde se ha llevado a cabo la construcción de un campo de golf de 17,68 Has. vinculado a la urbanización Sotoverde, habiéndose previsto también una reserva de suelo de aproximadamente 13,5 Has. para la construcción del futuro Centro Nacional del Rugby, con el cual los responsables de la Administración local pretenden que este núcleo situado al suroeste de Valladolid pueda convertirse en un referente a nivel nacional para este deporte (AYUNTAMIENTO DE ARROYO, 2003, 49).

En todo caso, independientemente de que este esfuerzo inversor pueda redundar en una intensificación aún mayor del proceso de urbanización, lo cierto es que tiene también un enorme valor desde el punto de vista del refuerzo de la cohesión social y territorial del municipio, y de cara a que pueda generarse un sentimiento de pertenencia al que en muchos casos es el nuevo lugar de residencia, para lo cual, obviamente, es absolutamente indispensable el mantenimiento del carácter público de este tipo de instalaciones. A pesar de estas ventajas, no debemos olvidar que se trata de equipamientos caracterizados por su elevado coste de mantenimiento y por ser muy exigentes en cuanto a consumo de agua, razón por la cual cuentan con numerosos detractores. En todo caso, su 
creciente proliferación en los entornos periurbanos constituye una realidad difícilmente remediable de acuerdo con el actual modelo de ordenación del territorio, puesto que tiende a primarse la autonomía local por encima de todo.

\section{La necesidad de definir un modelo de planificación territorial conce- bido a escala del conjunto de la aglomeración: ¿Una realidad posible o una utopía?}

En líneas generales, la estrategia que ha tenido un mayor éxito desde el punto de vista de la cooperación intermunicipal ha sido, sin lugar a dudas, la constitución de mancomunidades, pudiendo definirse como una fórmula asociativa de carácter temporal, cuya creación obedece a la incapacidad material y económica de muchas pequeñas localidades para hacer frente por sí mismas a la prestación de todos o alguno de los servicios mínimos de su competencia según está establecido en la Ley de Bases de Régimen Local ${ }^{7}$. Esta estrategia, tal y como señala Javier Navarro Luna, habría alcanzado una notable relevancia en nuestro país, y sobre todo en el caso de Castilla y León, tanto en lo que se refiere al número de municipios, como en lo que respecta a la población asistida (NAVARRO, 2001, 633-641).

Así, según los datos manejados por este autor, procedentes, a su vez, del Censo de entes del MAP, a comienzos del año 1999 España contaba con un total de 882 mancomunidades que abarcarían 5.614 municipios y atenderían las necesidades de casi 20,5 millones de habitantes. Más del 30\% de los núcleos mancomunados corresponderían a Castilla y León, repartidos en un total de 210 entidades, aunque sólo darían servicio al 9,7\% de la población, siendo especialmente significativo el hecho de que buena parte de los mismos no se localizan en áreas deprimidas del interior o de montaña, sino en ámbitos dinámicos, como es el caso de los entornos de las grandes y medianas ciudades.

Un magnífico ejemplo lo encontramos, una vez más, en el periurbano vallisoletano, cuyos municipios se encuentran agrupados en diversas mancomunidades con fines y objetivos muy similares. En concreto, Arroyo de la Encomienda pertenecería a dos de estas entidades, de manera que, por un lado, estaría integrado junto con la capital y la mayor parte de los núcleos de su entorno en la "Mancomunidad Tierras de Valladolid" para la recogida y tratamiento de resi-

\footnotetext{
${ }^{7}$ Las Mancomunidades de municipios aparecen reguladas en el artículo 44 de la Ley 7/1985, de 2 de abril, Reguladora de las Bases del Régimen Local, el cual señala que "Se reconoce a los municipios el derecho a asociarse con otros en mancomunidades para la ejecución en común de obras y servicios determinados de su competencia...". Por su parte, la Ley 1/1998, de 4 de junio, de Régimen Local de Castilla y León dedica todo su Título VI a la regulación de éstas y otras entidades asociativas.
} 
duos sólidos urbanos y, a su vez, pertenecería también a la "Mancomunidad Torozos", en la cual se hallan diversas localidades de la provincia, no todas incluidas en el ámbito periurbano, pero ya no está la ciudad central. Los servicios gestionados por esta asociación son mucho más diversos: limpieza de redes de alcantarillado, mantenimiento del alumbrado público, parques y jardines, etc.

No obstante, a pesar de la más que evidente utilidad de estas entidades para compartir el coste de la prestación de diversos servicios públicos, o para diseñar de forma coordinada la construcción de nuevas infraestructuras que puedan dar servicio al conjunto de la aglomeración, lo cierto es que la solución de los problemas que comienzan a esbozarse ya claramente en el periurbano de las ciudades medias actuales, tanto por la creciente extensión del mismo, como por su mayor relevancia, demandan un mayor nivel de cooperación y consenso entre los núcleos que los conforman, y sobre todo, entre éstos y la ciudad central. Se trata, por tanto, de avanzar un paso más allá de la solución mancomunada, que, como apunta José María Feria Toribio, exigiría, por un lado, la existencia de instrumentos de ordenación del territorio planteados a escala supramunicipal y, por otro, la creación de una estructura político-administrativa que permita desarrollar una planificación territorial concebida a nivel del conjunto de la aglomeración (FERIA, 1999, 309-316).

En todo caso, lo cierto es que la mayor parte de las ciudades medias españolas disponen ya de unas directrices de ordenación del territorio de ámbito supramunicipal, como es el caso de las DOTVAENT en Valladolid, pero no ocurre lo mismo en cuanto a la existencia de una estructura administrativa con capacidad real de intervención en ese ámbito territorial ${ }^{8}$. Un ejemplo de ello serían las denominadas Áreas Metropolitanas, cuya posibilidad de creación aparece ya recogida en la Ley estatal de Bases de Régimen Local de 1985 y de las cuales

\footnotetext{
${ }^{8}$ Las Directrices de Ordenación del Territorio de Valladolid y Entorno (DOTVAENT), aprobadas por la Junta de Castilla y León en el año 2001, fueron concebidas como un instrumento de ordenación territorial de carácter coordinador y director, capaz de orientar las decisiones urbanísticas con alcance supramunicipal o estratégico en Valladolid y en 23 municipios de la provincia, en torno a su capital. Ello permitiría consolidar el potencial de la ciudad y su ámbito de influencia como espacio metropolitano emergente (Instituto de Urbanística Uva, 1998, 41). Sin embargo, pese a sus nobles intenciones, el modelo de organización territorial preconizado en este texto y muchas de las directrices recogidas en el mismo en cuanto a movilidad y transporte, urbanismo, infraestructuras de servicios básicos, protección del medio ambiente y gestión y gobierno del territorio no se han podido aplicar en la práctica, ya que las corporaciones locales afectadas han "olvidado" o "recordado" la existencia de este documento a su más absoluta conveniencia.
} 
existen algunas experiencias destacables en las principales ciudades españolas, como es el caso de Madrid, Barcelona, Valencia y Bilbao?.

El principal problema radica en que si hay algún elemento común que caracteriza a estas iniciativas es que todas ellas han acabado siendo suprimidas, lo que habría suscitado un cierto recelo en cuanto a las posibles ventajas de las mismas en otros ámbitos. No obstante, como apunta Laureano López Rodó, la extinción de las corporaciones metropolitanas habría obedecido, esencialmente, a la transferencia de sus funciones y competencias a los gobiernos regionales con ocasión de la creación del Estado de las Autonomías (LÓPEZ, 1995, 85-95). De esta forma, no puede decirse que su desaparición haya sido consecuencia, en ningún caso, de una supuesta ineficacia o falta de operatividad de las mismas.

En este sentido, ya desde hace varios años se está debatiendo la posibilidad de crear un Área Metropolitana para la aglomeración vallisoletana, lo cual, como hemos comentado, sería muy interesante de cara a lograr la máxima racionalidad en la gestión de servicios públicos extensibles al conjunto del periurbano, así como de cara a la planificación de nuevas áreas residenciales, zonas industriales, equipamientos comerciales, etc. En definitiva, se trataría de un instrumento sumamente importante para que Valladolid pueda situarse en una posición privilegiada dentro del conjunto de ciudades medias españolas, aprovechando, a su vez, las expectativas generadas en torno a la próxima llegada del Tren de Alta Velocidad.

Sin embargo, plantearse la creación de un organismo con estos objetivos resulta extraordinariamente complicado por la dificultad relativa a la delimitación de la autonomía que debería tener este nuevo instrumento para cumplir su finalidad (BARRERO, 1993, 279-283). Por un lado, debemos tener presente que las competencias en materia de ordenación del territorio corresponden al gobierno autonómico y, por otro, hay que tener en cuenta que la Ley de Bases de Régimen Local concede a los municipios un alto grado de capacidad de decisión, al cual difícilmente estarán dispuestos a renunciar cuando fuese necesario adoptar una decisión que pudiera ir en contra de sus intereses. A ello hay que añadir la

\footnotetext{
${ }^{9}$ La ya mencionada Ley 7/1985, de 2 de abril, Reguladora de las Bases del Régimen Local, señala en su artículo 43 que: "Las Comunidades Autónomas, previa audiencia de la Administración del Estado y de los Ayuntamientos y Diputaciones afectados, podrán crear, modificar y suprimir, mediante ley, Áreas Metropolitanas, de acuerdo con lo dispuesto en sus respectivos Estatutos ". Estas mismas determinaciones aparecen recogidas en el artículo 45 de la también mencionada Ley 1/1998, de 4 de junio, de Régimen Local de Castilla y León, si bien en el caso de la legislación autonómica se sustituye el término de "Área metropolitana" por el de "Entidad metropolitana".
} 
existencia de una Diputación Provincial, que también posee su propio alcance competencial.

Este maremágnum administrativo constituye, por tanto, el principal escollo para la creación de una entidad supramunicipal con estos fines. Es por ello que, incluso desde las DOTVAENT, se alude a las dificultades que tendría una iniciativa de este tipo para llegar a ser viable y se insiste en que la opción más razonable sería potenciar la creación de una "Mancomunidad de la Comarca de Valladolid y Entorno" que agrupase a la capital y a la totalidad de los municipios del periurbano, los cuales, hoy en día, se hallan integrados en varias entidades distintas, pero con idéntico propósito (INSTITUTO DE URBANÍsTICA UVA, 1998, 273). No obstante, se trataría de una solución parcial a los problemas existentes, puesto que estaría limitada, en el mejor de los casos, al desarrollo de infraestructuras y a la gestión de servicios comunes, de manera que no permitiría desarrollar una planificación territorial integrada en el conjunto de la aglomeración.

Esta es la solución que defiende también el Ayuntamiento de Valladolid, ya que, aunque no es una opción plenamente satisfactoria, se considera la única que puede ser factible a tenor de las dificultades reseñadas. Así lo manifestó el alcalde de Valladolid, D. Javier León de la Riva, a propósito de la creación del denominado "Foro de alcaldes del alfoz", el cual nació a comienzos de 2005 con el propósito de ser un escenario que permita el estudio y el debate de los problemas que afectan al conjunto de la aglomeración como consecuencia del vertiginoso crecimiento de la superficie urbanizada en los últimos años, así como la búsqueda de las mejores soluciones posibles a los mismos. Esta institución promovida por los alcaldes de Arroyo, Zaratán y Geria, estaría integrada originariamente por un total de 17 ayuntamientos del periurbano vallisoletano más la propia capital, a la que se asignó la primera vocalía en la Junta Directiva. Sin embargo, tras la primera reunión, sus representantes declinaron participar en dicho organismo ante la falta de acuerdo en relación al peso que debía tener la ciudad central en las decisiones y los acuerdos adoptados ${ }^{10}$.

Recientemente, el alcalde vallisoletano ha manifestado la posibilidad de que la capital vuelva a unirse a este foro con la condición de que las decisiones adoptadas no resulten vinculantes, lo cual tampoco es, ni mucho menos, la solución ideal, pero al menos reforzará el interés y la utilidad de esta institución. Pese a todo, no cabe esperar que los acuerdos alcanzados por los distintos representantes en las sucesivas reuniones a celebrar tengan una gran trascendencia, ya que habrán de respetar por un lado la autonomía de los municipios $\mathrm{y}$, por

${ }^{10}$ El Norte de Castilla, 25-02-2005, 6-04-2005 y 6-07-2005. 
otro, las limitaciones existentes en cuanto a la disponibilidad de recursos económicos.

\section{CONCLUSIONES}

No cabe duda de que el intenso desarrollo urbanístico que ha caracterizado al periurbano vallisoletano en las últimas dos décadas ha supuesto una alteración morfológica, social y funcional de primer orden en los municipios limítrofes con la capital, inaugurando así un proceso que, en tanto en cuanto se mantenga la actual coyuntura favorable del mercado inmobiliario y el vigente modelo de ordenación territorial, puede calificarse a todas luces de imparable. Esta situación, que no es ni mucho menos desconocida en nuestro país, ha sido la principal responsable de que multitud de nuevas promociones residenciales de mayor o menor entidad hayan pasado a dominar un paisaje que hasta hace poco se caracterizaba por el predominio casi en exclusiva de explotaciones agrarias de distinto cariz. Junto a ellas también se han ido consolidando otras formas de ocupación del suelo, algunas de las cuales apenas tenían entidad a comienzos de los años noventa, pero que, en conjunto, han convertido al entorno de la ciudad en un ámbito multifuncional, percibido, a su vez, como un espacio de oportunidad.

Indudablemente, este modelo de crecimiento conlleva una serie de efectos positivos para los habitantes de los núcleos afectados, ya que pueden disponer de una serie de equipamientos e instalaciones básicas de las que antes se carecía, lo que obligaba a su población a tener que desplazarse a la capital para poder acceder a ellas. Asimismo, el incremento demográfico permite una mejora generalizada de las infraestructuras de transporte y, por ende, de la conexión con la ciudad central, reduciéndose así el tiempo empleado en los trayectos diarios, a la vez que también posibilita un aumento de la oferta de servicios de carácter privado, apareciendo nuevos comercios, supermercados, etc., que buscan satisfacer el incremento de la demanda generado en estas localidades.

Sin embargo, pese a estas ventajas, resulta imposible obviar la existencia de diversos inconvenientes, entre los que habría que destacar su considerable impacto ambiental y paisajístico, ya que la elevada proporción de vivienda unifamiliar en las nuevas promociones ha supuesto la desaparición de buena parte de las áreas con cierto atractivo ecológico en el entorno de las ciudades, así como la marginación casi absoluta de la actividad agraria. En segundo lugar, debemos tener presente que este proceso ha suscitado también una fuerte competencia por la propiedad del suelo próximo a la capital, tal y como se ha puesto de manifiesto a lo largo de estas páginas, dando lugar a numerosos conflictos, sobre todo en aquellos ámbitos dotados de una mayor accesibilidad gracias al desarrollo de las infraestructuras de transporte. 
Estas últimas están conociendo una intensidad de uso cada vez mayor, lo que está ocasionando un aumento de la contaminación e importantes problemas de congestión en las principales vías de entrada a la ciudad, siendo una buena muestra de cómo los problemas ligados al modo de producción de ciudad dominante en la actualidad han adquirido tal entidad que ya no puede afirmarse que afecten a las áreas periurbanas en sentido estricto, sino que se habrían extendido al conjunto de la aglomeración. Así, de cara a los próximos años se plantean numerosos interrogantes, como por ejemplo, si los escasos recursos disponibles a escala local serán suficientes para mantener un modelo de desarrollo urbanístico presidido por las bajas densidades edificatorias, las consecuencias derivadas de la carencia de suelo para satisfacer las nuevas necesidades que puedan surgir en concepto de infraestructuras, servicios, etc., o ya en la propia capital debemos plantearnos qué puede hacerse con aquellos barrios construidos durante los años cincuenta y sesenta para alojar a la población que llegaba del campo para trabajar en la industria y que ahora se han convertido en los principales emisores de población que nutre este fenómeno.

Para dar respuesta a todas estas cuestiones el planeamiento urbano debe tener un papel fundamental, no sólo en el ámbito local, donde ha de velar por el desarrollo de estrategias que eviten la segregación social y funcional claramente apreciable en numerosos núcleos del área periurbana, sino también a escala supramunicipal, definiendo un modelo de ordenación territorial capaz de satisfacer las necesidades y problemas del conjunto de la aglomeración. En este último caso el problema surge cuando se plantea la creación de una estructura políticoadministrativa con capacidad real de intervención en ese ámbito territorial.

Una posible vía para alcanzar este objetivo sería la creación de un Área Metropolitana para la aglomeración vallisoletana, lo que permitiría lograr la máxima racionalidad en la gestión de servicios públicos extensibles al conjunto del periurbano, así como también en la planificación de nuevas áreas residenciales, zonas industriales, equipamientos comerciales, etc. Sin embargo, el hecho de que las competencias en materia de ordenación del territorio correspondan al gobierno autonómico y, sobre todo, el elevado techo de competencias que poseen los municipios en materias de vital importancia, como el urbanismo, hacen que sea prácticamente imposible conseguir la constitución de una entidad supramunicipal con esta finalidad.

De este modo, la única alternativa viable consiste en potenciar la creación de una única mancomunidad que agrupe a la capital y a la totalidad de los municipios de su periurbano. $\mathrm{O}$ dicho de otro modo, mientras no exista una cesión de soberanía por parte de las corporaciones locales en lo que se refiere a cuestiones trascendentales que en la actualidad son claramente de su competencia, sólo será posible llegar a acuerdos en cuanto al desarrollo de infraestructuras o a la 
gestión de servicios comunes, pero nunca será posible llevar a la práctica un modelo de ordenación del territorio concebido a escala del conjunto de la aglomeración.

Así pues, el problema no es tanto la falta de propuestas para intervenir en el ámbito periurbano (Buen ejemplo de ello son las DOTVAENT en Valladolid), sino, sobre todo, la falta de interés real en llevarlas a la práctica, ya que, como hemos visto, los diversos usos y actividades que compiten por ocupar el suelo del entorno de las ciudades generan importantes beneficios para las arcas de los municipios limítrofes con la capital. Unos ingresos a los que los responsables políticos de estos núcleos, ya sean de un signo u otro, difícilmente estarán dispuestos a renunciar en favor del mejor funcionamiento del conjunto, y mucho menos aún de forma voluntaria. Es por ello que, siendo realistas, pocas esperanzas cabe albergar en cuanto a la introducción de un mínimo de racionalidad en el proceso de crecimiento urbano periférico dominante en las ciudades medias en la actualidad, al menos a corto y medio plazo.

\section{BIBLIOGRAFÍA}

AYUNTAMIENTO DE ARROYO DE LA ENCOMIENDA (2003): Memoria de Actividades del Ayuntamiento de Arroyo de la Encomienda: 2002, Arroyo de la Encomienda, Valladolid, $86 \mathrm{p}$.

AyUNTAMIENTO DE VALlAdolid (2004): Plan Municipal de Vivienda y Suelo 2004-2007, Valladolid, $186 \mathrm{p}$.

BARRADO TIMÓN, D. A. (1998): «Implicaciones territoriales de las instalaciones deportivo-recreativas periurbanas: El caso de la Comunidad de Madrid», Ciudad y Territorio. Estudios Territoriales, $\mathrm{n}^{\mathrm{o}}$ 115, pp. 145-162.

BARRERO RODRÍGUEZ, M. C. (1993): Las áreas metropolitanas, Civitas, Madrid, $283 \mathrm{p}$.

CALDERÓN CALDERÓN, B. (2002): «El espacio interminable: Justificación, promoción y venta de los nuevos paraísos residenciales en la ciudad española» (en) BERNAL SANTA OlALlA, B. (Coord.): El medio ambiente en las ciudades históricas. IV Jornadas de Geografia Urbana, Universidad de Burgos, Burgos, pp. 43-63.

De Miguel GonZÁLEZ, R. (1994): «Estado de la periurbanización en Francia: el caso de Nancy», Geographicalia, n 31, pp. 53-69.

FERIA TORIBIO, J. M. (1999): «Nuevas periferias urbanas y planificación pública» (en) DomíNGUEZ RodRíGUEZ, R. (Coord.): La ciudad. Tamaño y crecimiento, AGE y Universidad de Málaga, Málaga, pp. 309-316.

GARCÍA-BELLIDO GARCÍA DE DIEGO, J. (2002): «La cuestión rural: patología urbanística del espacio rústico», Ciudady Territorio. Estudios Territoriales, $\mathrm{n}^{\mathrm{o}} 132$, pp. 277-322. 
GARCÍA FERNÁNDEZ, J. (2000): Valladolid: De la ciudad a la aglomeración, Ariel, Barcelona, $350 \mathrm{p}$.

GONZÁLEZ URRUELA, E. (1985): «Consumo de espacio y dominación territorial en Valladolid», Ciudad y Territorio, ${ }^{0}$ 65, pp. 17-36.

INSTITUTO DE URBANÍSTICA DE LA UNIVERSIDAD DE VALLADOLID (1998): DOTVAENT; Avance de Directrices de Ordenación Territorial de Valladolid y su Entorno, Junta de Castilla y León, Consejería de Medio Ambiente y Ordenación del Territorio, Valladolid, $287 \mathrm{p}$.

LÓPEZ DE LUCIO, R. (1994): «Accesibilidad y nuevas centralidades», Alfoz, ${ }^{\circ}$ 109, pp. 71-77.

LÓPEZ RODÓ, L. (1995): «Apuntes sobre la organización institucional de las áreas metropolitanas», Situación, no 3, pp. 85-95.

LÓPEZ TRIGAL, L. (1998): "Áreas urbanas y ciudades medias de Castilla y León», Revista Medio Ambiente en Castilla y León, ${ }^{\circ}$ 9, primavera-verano, pp. 44-49.

MONCLÚS, F. J. (Ed.), (1998): La ciudad dispersa: suburbanización y nuevas periferias. Urbanismo, ciudad, historia (I), Centre de Cultura Contemporania de Barcelona, Barcelona, $223 \mathrm{p}$.

NAVARRO LUNA, J. (2001): "Las mancomunidades de municipios en España. Una estrategia territorial de escala intermedia" (en) MANERO, F. (Coord.): Espacio natural y dinámicas territoriales, Libro Homenaje a Jesús García Fernández, Universidad de Valladolid, Valladolid, pp. 633-641.

RODRÍGUEZ LÓPEZ, J. (2003): «Vivienda: la expansión persistió en 2002», Ciudad y Territorio. Estudios Territoriales, nº 135, pp. 163-183. 
Figura 1. Situación de Arroyo de la Encomienda en el contexto de la aglomeración vallisoletana

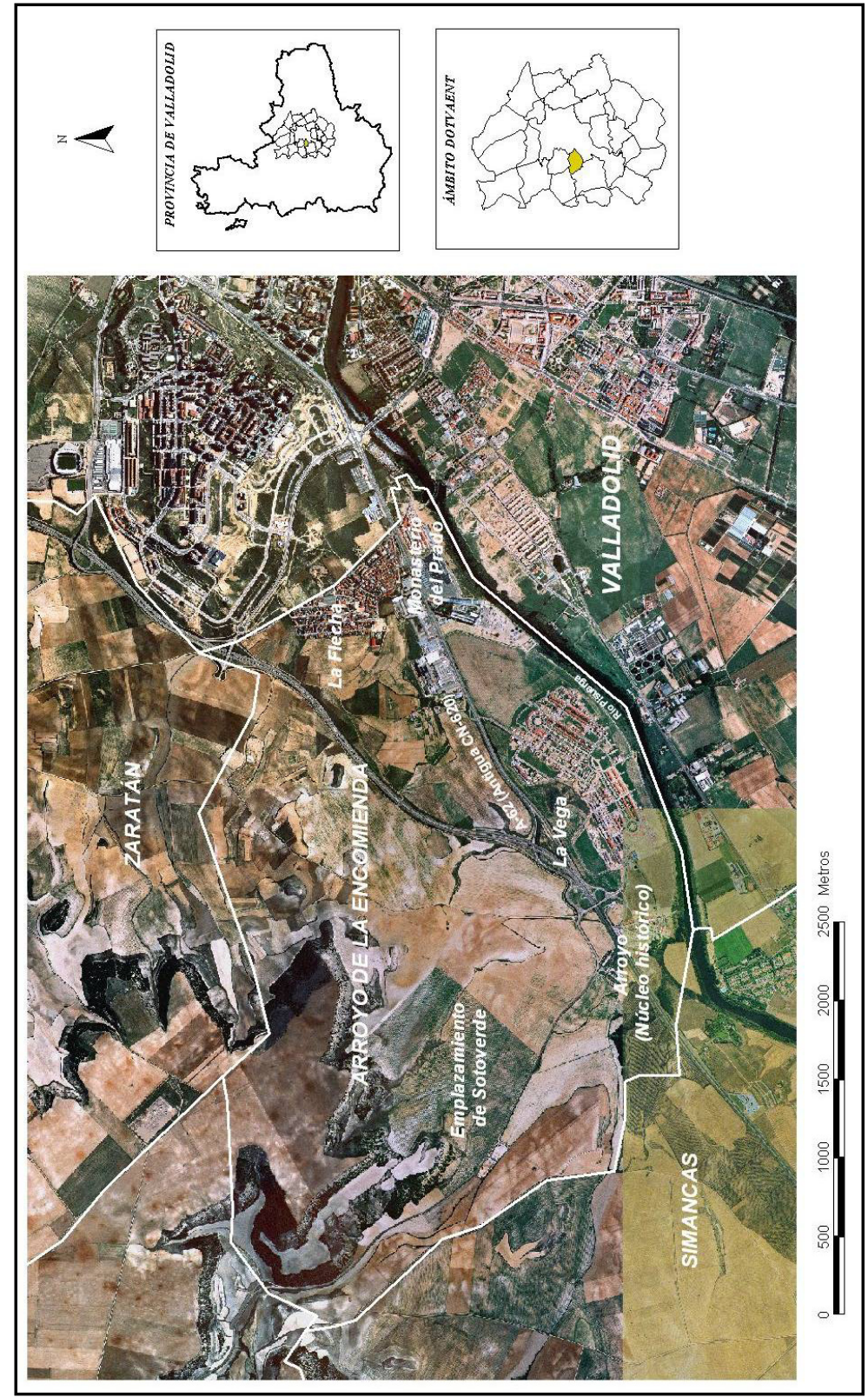

FUENTE: Fotografías aéreas, 1999. 
Figura 2. Agentes, factores responsables y principales impactos derivados de la transformación del ámbito periurbano

\section{FACTORES RESPONSABLES}

\section{AGENTES}

- Promotores (locales y foráneos)

- Propietarios del suelo rústico o no urbanizable

- Administración local

- Compradores de las viviendas
- Apetencia de nuevos espacios para vivir con atractivo paisajístico.

- Búsqueda de suelo accesible y barato por parte de un creciente número de actividades económicas.

- Elevado coste del suelo en la ciudad central.

- Importantes beneficios para propietarios del suelo y promotores.

- Normativa urbanística favorable.

- Gran interés de las administraciones locales.

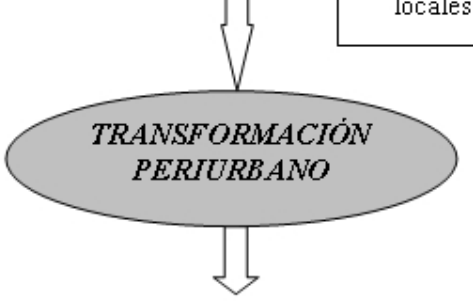

PRINCIPALES MMPACTOS DERIVADOS

- Elevados costes ambientales y paisajísticos.

- Aparición de conflictos entre diversos usos del suelo y actividades.

- Congestión de infraestructuras de transporte.

- Necesidad de mejorar servicios y dotaciones urbanísticas obsoletas. 
Figura 3. Nueva promoción residencial en el núcleo de La Flecha.

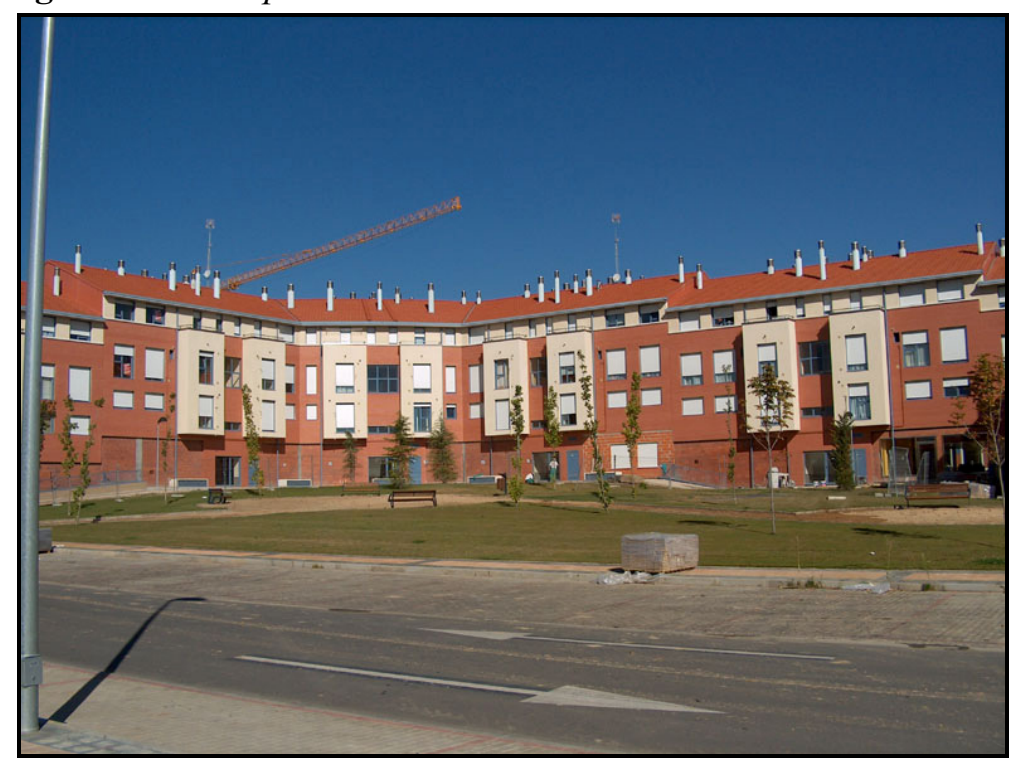

Figura 4. Vista general del conjunto residencial Sotoverde. Finales de 2004.

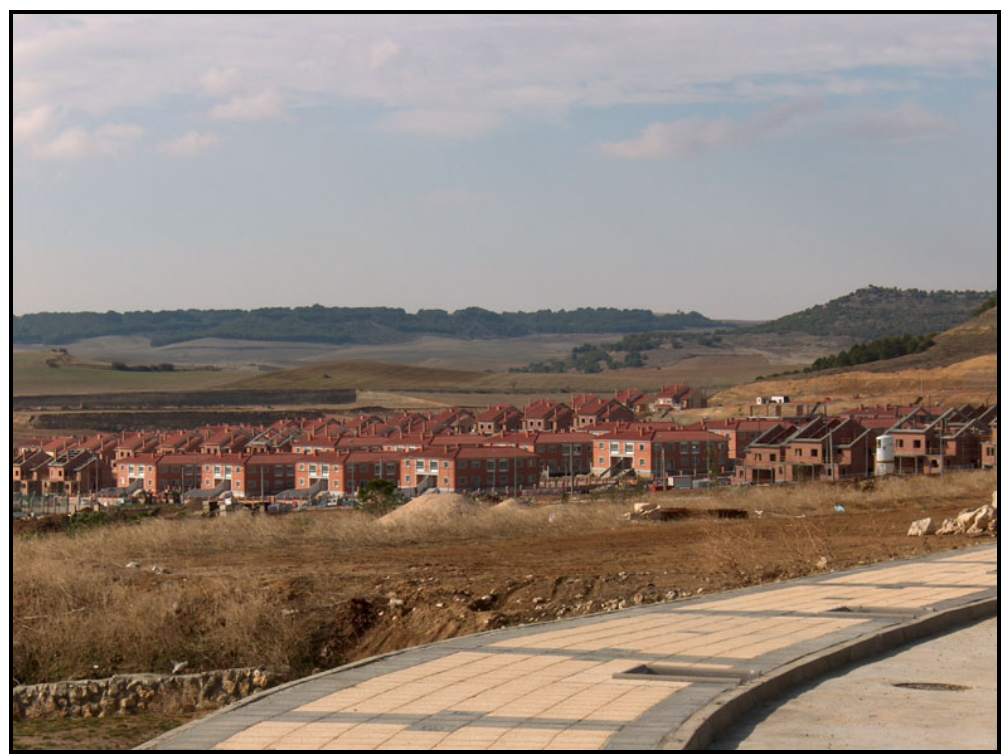

Polígonos. Revista de Geografia, 15 (2005); pp. 7-35 
La configuración del espacio periurbano como escenario de competencia...

Figura 5. Unidades de sustitución y nuevos polígonos industriales en Arroyo de la Encomienda

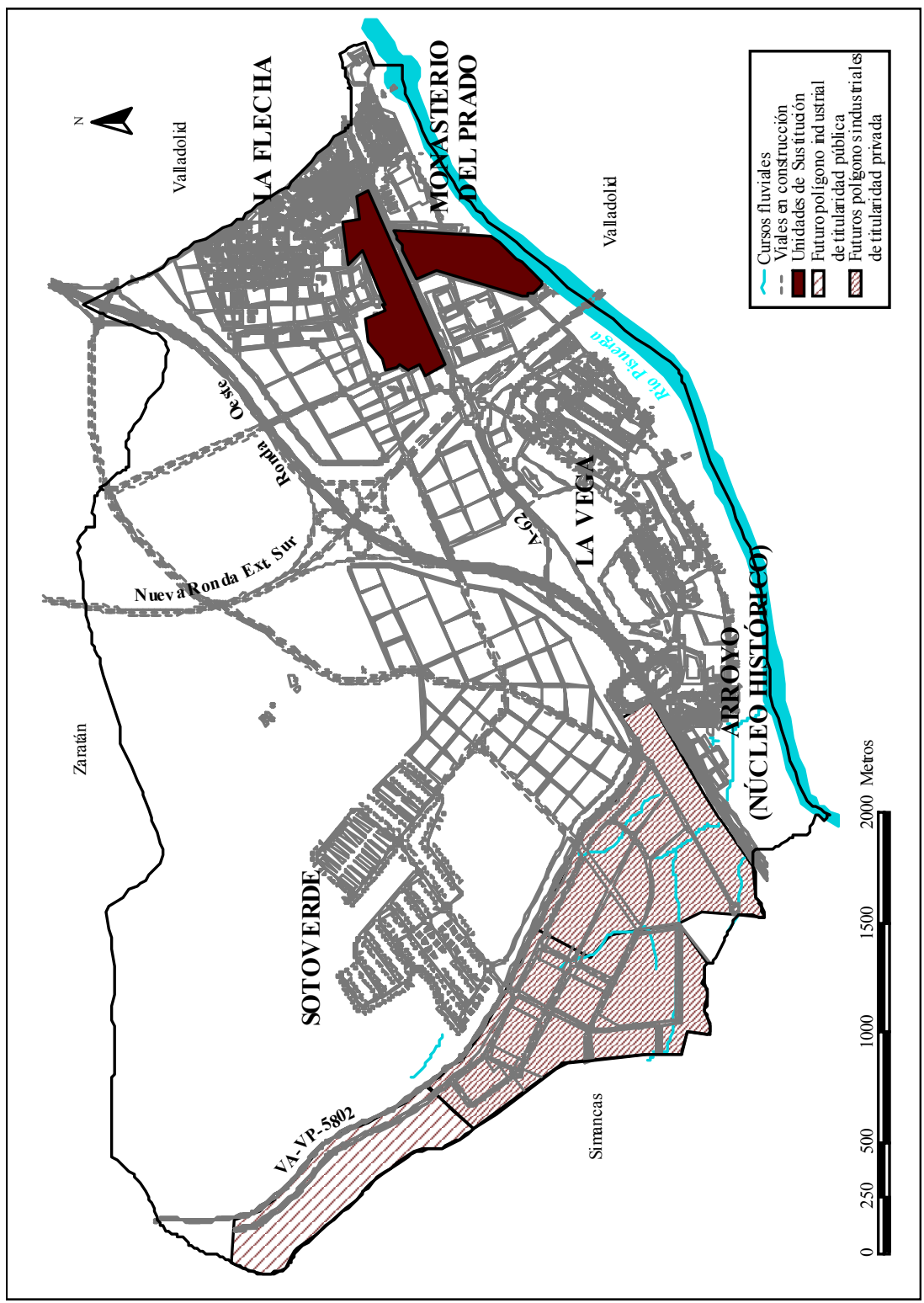

FUENTE: P.G.O.U. de Arroyo de la Encomienda, 2003. Elaboración Propia. 